\title{
Medicinal Uses of Licorice (Glycyrrhiza glabra L.): AComprehensive Review
}

\author{
Sana Noreen ${ }^{1}$, Fizza Mubarik ${ }^{1}$, Fatima Farooq ${ }^{1}$ (D) Mudassir Khan $^{2} \mathbb{D}$, Ahasan Ullah Khan Kan $^{3,4}$, Yunita Sari Pane ${ }^{5 *}$ (D) \\ ${ }^{1}$ University Institute of Diet and Nutritional Sciences, The University of Lahore, Lahore, Punjab, Pakistan; ${ }^{2}$ Department of \\ Healthcare Biotechnology, Atta-Ur-Rahman School of Applied Biosciences, National University of Science and Technology, \\ Islamabad, Pakistan; ${ }^{3}$ Department of Entomology, Faculty of Agriculture, Sylhet Agricultural University, Sylhet, Bangladesh; \\ ${ }^{4}$ Department of Agroforestry and Environmental Science, Climate-Smart Agriculture Lab, Faculty of Agriculture, Sylhet \\ Agricultural University, Sylhet, Bangladesh, ${ }^{5}$ Department of Pharmacology and Therapeutics, Faculty of Medicine, Universitas \\ Sumatera Utara, Medan, Indonesia
}

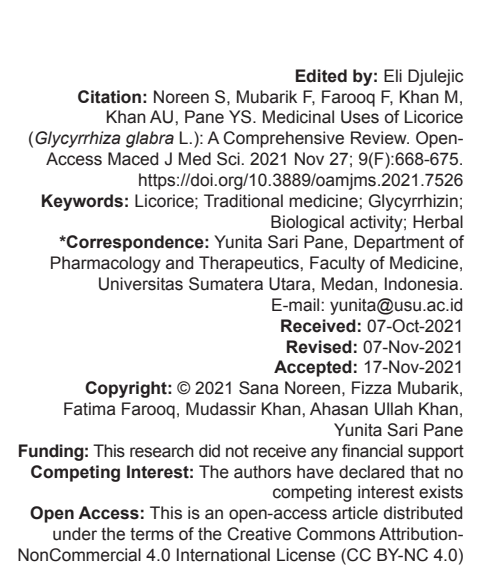

\section{Abstract}

Innumerable plants have been used widely as integral medicinal sources since the start of human civilization. The demand for herbal medicines is constantly increasing with time overtime. Licorice (Glycyrrhiza glabra family Leguminosae) is one of the most used herbal plants in foods, in medicinal forms, and substantially researched on a worldwide scale. It was used as traditional and complementary medicine against innumerable ailments including allergies, liver toxicity, gastric ulcer, lung diseases, skin disorders, oral health problems including tooth decay, and inflammation. The constituents of licorice include various essential oils, sugars, inorganic salts, resins, amino acids and nucleic acids. Biological activity has been observed to be portrayed by active compounds of licorice including triterpene, flavonoids, and saponins. In recent years, licorice has been widely researched to discover its benefits, constituents, and its mechanism of action. The review summarizes the therapeutic and pharmacological benefits of licorice and its uses in different health-related conditions along with its toxicity and maximum levels of licorice consumption.

\section{Introduction}

Many plants are being used as spices and medicines because of their various pharmacological benefits over the centuries. These plants possess many functional properties because of being an enriched source of several bioactive compounds. Humans consume these plants and their extracts as healthy additives in their daily diet [1].

Glycyrrhizin is the major ingredient present in licorice, the root of Glycyrrhiza glabra. This compound has been used as traditional plant-based medicine as well as a sweetener and additional flavor in candies, drinks, and foods in Asian, the US, and European countries [2]. In addition, glycyrrhizic has a slow sweetness onset and is being used as a preferred natural sweetener as it is 50-100 times sweeter than sucrose. Because of its sweet taste, a Greek physicist, Pedanius Dioscorides, named licorice "sweet root" [3]. In addition to being used as a natural sweetener, licorice is also being used as a potential therapeutic herb. Various metabolites such as glycyrrhetinic acid and glycyrrhizic acid are mainly responsible for the pharmacological effects of licorice. Glycyrrhizic acid is further converted to glycyrrhetic acid, a triterpenoid aglycone conjugated to glucuronide and sulfate, which is 200-1000 times more integral inhibitor of 11b-hydroxysteroid dehydrogenase (11bHSD) [4].

The biologically active compound of licorice, glycyrrhizic acid, is being used as a plant-based medicine for many diseased conditions due to its neuroprotective, anti-inflammatory, antiviral, and anticarcinogenic properties [5]. Many clinical studies have provided scientific evidence regarding the pharmacological properties of licorice against many disease conditions. Various studies concluded that licorice treats glucose intolerance and improves insulin sensitivity [6]. It is also suggested that licorice stresses adipose tissue formation, enhances energy expenditure, and possesses anti-cancer as well as antimicrobial effects [7]. Licorice has numerous health benefits which include its antiobesity, antidiabetic, antidepressant, anti-cancerous, hepatoprotective, anti-allergic, and many other beneficial effects (Figure 1). 
In addition to the major active compound glycyrrhizic acid, licorice also contains adequate amounts of saponins, isoflavonoids, flavonoids, chalcones, and triterpenes [8]. There is wide use of licorice in the production of alcoholic beverages, teas, confectionery, pharmaceutical, tobacco, and cosmetics industries all over the world [9].

Besides being a healthy herb without having any side effects on health when used within the dietary recommended allowance, misuse or over-consumption

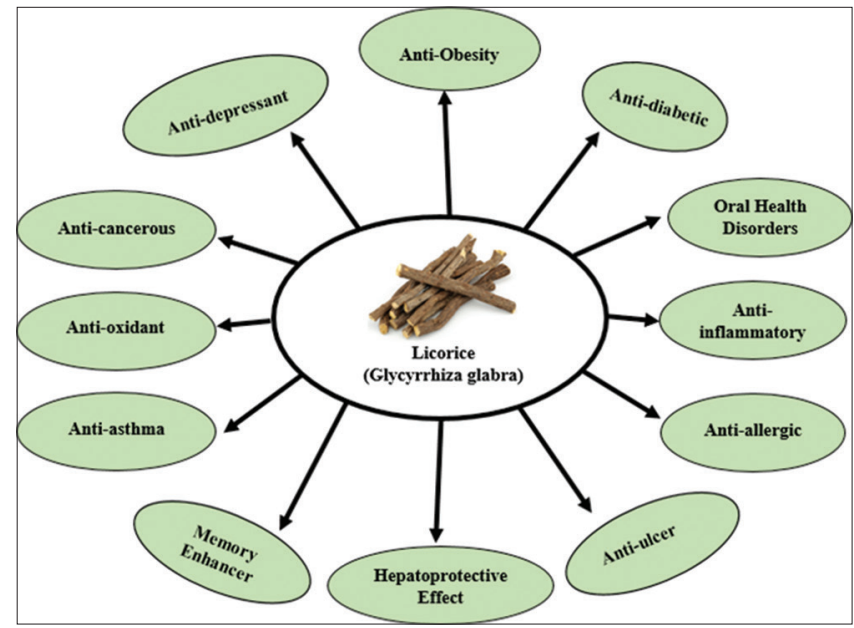

Figure 1: Health benefits of licorice

of glycyrrhizin could be hazardous for human health. In addition to having glucocorticoid-like activity, licorice also possesses an increased risk of mineralocorticoidlike activity by directly binding with mineralocorticoid receptors along with the blockage of $11 \beta-H S D$. Hence, continuous exposure to a high dose of glycyrrhizin may lead to an excess of mineralocorticoids along with suppression of the renin-angiotensin-aldosterone system. The effects may include metabolic alkalosis, hypokalemia, edema, cardiac arrhythmia, hypertension, and other mineralocorticoid-like activity-related conditions [10].

This review aims to summarize the therapeutic and pharmacological benefits of licorice (Table 1) and its uses in different health-related conditions along with the toxicity and maximum level of licorice consumption.

\section{Antidiabetic Effect of Licorice}

For thousands of years, many herbs have been used to prevent and treat diabetes and one of the oldest herbs, licorice, is also being used in Chinese medicine for herbal treatment due to its various pharmacological properties. Licorice plays a key role in the inhibition of certain changes caused by D-galactose including oxidative stress, insulin resistance, and free radical damage which lead to a significant delay in the progression and development of diabetes [11]. Many compounds isolated from licorice have been proved to possess antidiabetic effects and have a significant inhibitory effect on diabetes, such as glabridin, liquiritigenin, licochalcone (Lic) A, glycyrrhizin, Lic $\mathrm{E}$, glycyrrhetinic acid, isoliquiritigenin, and some flavonoids. Various studies suggested that the active components of licorice, amorfrutin, and chalcone, possess antidiabetic effects through stimulating the "activation of peroxisome proliferator-activated receptor gamma (PPAR $\gamma$ 's)," which plays a key role in adipocyte differentiation and carbohydrate and lipid metabolism. Furthermore, glucose intake is increased and glucose intolerance is prevented by glabridin, through the mechanism of enabling the translocation of glucose transporter type 4 through adenosine monophosphate protein kinase [12].

In a research study, rats with blood glucose level of $200 \mathrm{mg} / \mathrm{dl}$ were applied with $1 \mathrm{~g} / \mathrm{kg} /$ day licorice essence and citrate buffer was given to control group. After 8 weeks, the results showed that rats group given licorice essence had lower blood glucose levels. Another study conducted on diabetic rats concluded that Licochalcone $\mathrm{E}$ (Lic E), a compound isolated from licorice, elevated the levels of small adipocytes through the process of enhancing the activation of PPARY and produced positive impacts on adipocyte-oriented diabetics [13].

Anotherstudywascarriedoutonstreptozotocindiabetic rats, in which the anti-hyperglycemic effects of aglycone and 18ß-glycyrrhetinic acid were observed. An elevation in plasma glucose level and glycosylated haemoglobin, Hemoglobin A1c (HbA1c), however a decline in levels of plasma insulin and haemoglobin $(\mathrm{Hb})$ was observed. The results concluded that on administration of $18 \beta g$ lycyrrhetinic acid $(50,100$, or $200 \mathrm{mg} / \mathrm{kg} / \mathrm{body}$ weight $)$ or glibenclamide $(600 \mu \mathrm{g} /$ $\mathrm{kg} / \mathrm{body}$ weight) in $5 \%$ dimethyl sulfoxide orally for a duration of forty-five days can leads to a gradual improvement in diabetics [14]. The impact of extracts of licorice in albino mice was also analyzed. The study proved that Glycyrrhiza glabra possess antilipidemic and anti-hyperglycemic properties at low doses. Licorice extract can be potentially beneficial in order to prevent and treat diabetic nephropathy led by mesangial fibrosis and glomerulo-sclerosis by the process of blocking the activation of Akt and transformation of growth factor-b signaling [15]. The above mentioned studies provide an evidence that licorice can be used as a beneficial therapeutic agent for the diabetic treatment. 


\section{Anti-obesity Effect of Licorice}

Glabridin-enriched licorice essence caused a decline in adipose tissues through the process of reduction in the activity of acetyl-CoA carboxylase and an increase in activity of acetyl-CoA dehydrogenase of licorice flavonoid oil (LFO) and producing stress in the formation of adipose tissue in 3T3-L1 cells. Another mechanism involved in the relationship between licorice consumption and anti-obesity effects states that flavonoid oil of licorice enhances energy consumption through increasing beta-oxidation which causes a decline in fat mass and body fat by the process of lipogenesis prohibition. A research study proved that the administration of $600 \mathrm{mg}$ of LFO to healthy people can cause energy consumption elevation through a rise in the phenomenon of thermogenesis on the skin. A study conducted on "C57BL/6J rats fed with high-fat diet" concluded that consumption of LFO causes stress in the increase of abdominal fat tissue [16]

A study stated that LFO possess a positive impact weight management of over weight, fat and obese individuals. The effects of licorice on weight management may have resulted from various differences e.g., age, dietary intake, BMI, levels of physical activity, ethnic roots of individuals and type as well as the amount of licorice applied in the research study. Another study investigated the effects against obesity of frozen dried powder of ethanolic licorice extract on rats given high fat diet and have been induced with obesity and hyperlipidemia. The results stated that licorice powder had anti-obesity effects comparable to orlistat, which is a pancreatic lipase inhibitor. The effects of licorice powder against obesity appeared to be mediated by a decline in absorption of dietary fat from the intestine as dose of licorice powder lessened the increase in serum triglyceride levels and enhanced the excretion of fat content in feces [17].

\section{Hepatoprotective Effect of Licorice}

Licorice is being used as a traditional medicinal herb in order to treat a number of liver diseases. The secondary metabolites which have been derived from licorice can cause a reduction in serum liver enzyme levels and leads to an improvement in tissue pathology of hepatitis patients [18]. In a research study, several compounds isolated from G. glabra including glabridin, hispaglabridin $B$, isoflavan derivatives, hispaglabridin $A$, 3'-hydroxy-4'-O-methylglabridin, and 4'-O-methylglabridin were being investigated for their property of protecting mitochondria of the liver against oxidative stress.

In a research study it was proved that glycyrrhizic acid induced a vital reduction in levels of serum aminotransferases which then leads to an improvement in the liver histology. A study led to analysis that the aqueous extract of Glycyrrhizin glabra significantly improves functions of liver in acute liver disease even through a dose of $2 \mathrm{mg} / \mathrm{kg}$ body weight per day [19].

Glycyrrhetinic acid provides hepatoprotective effects against liver damage induced by retrorsine as well as hepatotoxicity induced by carbon tetrachloride $\left(\mathrm{CCL}_{4}\right)$. Glycyrrhizin is widely used for the preparation of medicines for the treatment of many liver diseases including cirrhosis of the liver, hepatitis $B$, liver fibrosis, and hepatitis $\mathrm{C}$. In various studies of in vivo animal models, the protective effects of glycyrrhizin against $\mathrm{CCL}_{4}$-induced liver injuries have been observed. Moreover, glycyrrhizin also provides protection against Xanthium-induced hepatotoxicity and liver fibrosis. Another study was carried out to evaluate the impact of licorice on chronic alcohol-induced fatty liver injury which is mediated by oxidative stress and inflammation. The results concluded that licorice showed positive response in chronic fatty liver injury induced by alcohol is mainly due to the enhancement of antioxidant defense of licorice [20].

\section{Anti-ulcer/Anti-Helicobacter pylori (H. pylori) Effect of Licorice}

The most common reason behind infections, oxidative stress, peptic ulcer, and gastric ulcer is $H$. pylori. Such conditions can be treated through antacids, histamine antagonists, and/or proton-pump inhibitors, but they do have many side effects including arrhythmias, hypertension, asthenia, and certain liver disorders. Hence, the use of natural medicinal herbs is usually preferred for the treatment among which licorice is the most commonly used therapeutic agent because of its antimicrobial effects and pharmacological properties. Licorice is mainly used for the treatment of peptic ulcers because of its antioxidant, anti-inflammatory, and prostaglandin formation booster effects [21].

Flavonoids enriched extracts of licorice reduce $H$. pylori activity through another potential mechanism of stressing synthesis of proteins and two enzymes; hydroxyl-folate reductase and DNA gyrase. Moreover, certain components of licorice possess the ability to increase mucus secretion in the alimentary canal and extend the lifetime of cell surfaces, creating an antipepsin effect in the stomach. In a study, it was observed that licosio-flavan B, licochalcone A, glabridin, licoricidin and glabrene inhibits the reproduction of Helicobacter pylori (H. pylori). Hence, licorice can be considered to possess anti-helicobacter pylori effects [22]. 


\section{Oral Health Disorders and Licorice}

Recently, several studies shown the positive effects of licorice and its active components such as glycyrrhizin, licoricidin, Lic A, and glabridin on tooth decay and oral health. Licorice is mainly used in this regard because of its antimicrobial property. Some food items consist of certain components resistant to Streptococcus mutans. Human intestinal bacteria transform glycyrrhizin into severe hypertensive material and glycyrrhizic acid may also cause hypertension, therefore, only glycyrrhizin-free licorice is being used for different studies [23].

Xerostomia that is dryness of the mouth is a common symptom in hemodialysis patients. It also affects the quality of life for patients along with oral health. In a research study, the effect of mouthwash intervention of pure water and licorice was compared in hemodialysis patients. The results showed that licorice mouthwash was more effective than pure water in relieving mouth dryness and increasing the flow rate of saliva [24].

\section{Memory Enhancement and Antidepressant Effects of Licorice}

The effectiveness of licorice in memory enhancement as well as an antidepreseeant has been clearly demonstrated through mouse immobility tests. The experiments carried out on depressed rat revealed that several metabolites of $G$. uralensis, mainly liquiritin possess anti-depressant effects on chronic stress. A research study conducted on mice revealed the anti-depressant effects of isoliquiritin and liquiritin, it was depicted that the mechanism of action of such compounds could be due to the increase in norepinephrine and 5-Hydroxytryptamine in the hippocampus, cortex and hypothalamus of mouse. In a research study, the anti-depressant activity of liquiritin and isoliquiritin has been reported in forced swimming test and tail suspension test in mice. The results showed an increase in the levels of 5-Hydroxytryptamine and norepinephrine in the hypothalamus, hippocampus and cortex of mice, which provides the mechanism of action of these compounds [25].

Among many compounds being isolated from licorice, the most effective compounds to improve memory and learning include 2,2,4-trihydroxychalcone and glabridin. This compound also antagonizes scopolamine-induced amnesia. According to an experiments conducted on rats, it was reported that this compound also plays a preventive role in the prevention of diabetes-induced deleterious effects on learning and memory [25]. A research study was conducted in order to investigate the effects of aqueous extract of licorice on dendritic morphology of hippocampal cornu ammonis area 3 neurons (CA3). The results depicted an obvious enhancement of dendritic intersections and dendritic arborization in hippocampul pyramidal neurons by the administration $225 \mathrm{mg} / \mathrm{kg}$ body wt. and $150 \mathrm{mg} / \mathrm{kg}$ body wt. of the treatment extract. This clearly demonstrates the neuronal dendritic growth stimulation properties of licorice aqueous extract [26]. These researches result in the fact that licorice and several compounds present in its extract can be utilized as a therapeutic drug to improve memory, dementia, impaired learning abilities and certain other neurodegenerative disorders.

\section{Effect of Licorice on Cancer}

Many natural products or their synthetic analogs are used as anti-cancer agents. Licorice contains flavonoids and triterpenes saponins as its main biologically active ingredients which provide many beneficial properties including antioxidant, antiinflammatory, and anti-cancer properties. Recently, studies have led to the observation that glycyrrhizic acid stresses AKT/mTOR signal on endometrial and breast cancer cells along with the inhibition of proliferation of leukemia cells. It is demonstrated through a broad spectrum of in vivo and in vitro studies that certain purified compounds and mixed extracts from licorice possess anticancer properties through inhibiting the proliferation, inducing cell cycle arrest, autophagy, differentiation, apoptosis, suppressing metastasis, angiogenesis, sensitizing radiotherapy, or chemotherapy. A significant reduction in the side effects of chemotherapeutics and an enhanced anticancer effect was also seen through a combination of clinical chemotherapy drugs with licorice compounds [27].

Anti-tumor activity of licorice was examined by the ratio of $\mathrm{CC}_{50}$ against human normal oral cells and the results concluded that the flavonoid-rich part of licorice exhibits cytotoxic effects against human oral squamous cell carcinoma cell lines as compared to normal cells. In an in vivo assay, licorice was observed to inhibit the proliferation of tumor cells along with inhibition of angiogenesis. The arrest of the G1 cell cycle and apoptosis was induced in MCF-7 human breast cancer cells by the ethanol extract of licorice. Glycyrrhizin and the ethanolic extract exhibit antiproliferative properties against MCF-7 in a dose-dependent manner. It was observed that Lic $\mathrm{E}$, an active ingredient from the roots of licorice, possesses the most potent cytotoxic effects as compared to other well-known anti-cancer agents [28].

Several compounds derived from licorice, including "topazolite, gancaonin $\mathrm{P}$, gancaonin $\mathrm{O}$, Lic $B$, and glyasperin A," exhibited increased cytotoxic 
activity against human oral squamous carcinoma cell line HSC-2. Moreover, isoliquiritigenin also inhibited the growth of prostate cancer and is an effective cancer chemopreventive agent through the induction of phase II enzymes such as quinone reductase-1 in murine hepatoma cells. Lic $A$, an active ingredient found in licorice, has shown the suppression of oxidation of cells along with a remarkable inhibitory effect on the proliferation of cancer cells. Hence, many studies suggested that bioactive compounds in licorice can be used as effective anti-cancer and antiproliferative agents [29].

\section{Effect of Licorice on Asthma}

Asthma is a common respiratory disorder these days. Corticosteroids are commonly used during asthma to inhibit inflammation. However, long-term use of such drugs may cause many side effects on human health. For a long time in history, licorice has been observed to be used for the treatment of bronchial asthma. One of the active compounds in licorice, Lic A, is considered to exhibit anti-asthma activity. Asthma is majorly caused by a cytokine known as thymic stromal lymphopoietin (TSLP). Expression of TSLP can be controlled by a nuclear factor kappa B (NF-kB). Lic A was observed to inhibit the activation of NF-kB, caused by tumor necrosis factor $\alpha$ (TNF $\alpha$ ), through the inhibition of activation of IkB kinase complex [30].

Many studies suggested that flavonoids in licorice suppress eosinophilic lung inflammation, levels of immunoglobulin (IgE), interleukin (IL)-13, IL-5, IL-3, and increase activity of interferon gamma. Another compound ganoderic acid, isolated from licorice, possesses an anti-asthma effect by stressing TNF $\alpha$. $A$ research was conducted to determine the effects of an active compound found in licorice, glycyrrhizin, on histopathologic features of the lung in BALB/c mice. The results of the study concluded that the treatment group receiving glycyrrhizin exhibit amelioration of all established lung histopathologic changes in the mouse model of asthma. Therefore, Lic A and glycyrrhizic acid, the active components of licorice, can be used in the treatment of asthma [31].

\section{Effect of Licorice on Skin Disorders}

Due to many pharmacological effects of licorice including anti-allergenic, anti-immune-mediated cytotoxicity, antioxidant, and anti-inflammatory, many kinds of research were carried out to determine the influence of glycyrrhizin on the underlying inflammation of certain skin-related disorders. It was reported that shaving and ultraviolet (UV) light-induced erythema can be significantly reduced by the application of a topical gel containing Lic $A$, which is a derivative of glycyrrhizin. In a questionnaire-based assessment, the use of Lic A indicated a significant improvement in erythema and quality of life. Glycyrrhizin is also being used to relieve type 1 allergic diseases induced by $\lg E$, such as allergic dermatitis. Among 90 patients with atopic dermatitis, licorice gel dose dependently led to a reduction in edema, erythema score, and itching sense (placebo vs. treatment group and $1 \%$ vs. $2 \%$ licorice gel, all $P<$ $0.01)$. Some patients are resistant to the topical steroid which is commonly used to treat atopic dermatitis. However, the use of glycyrrhizin led to an increase in antibody formation, cortisol-induced stress reaction inhibition, and inflammation. Hence, glycyrrhizin has the potential to be suggested as an effective treatment for atopic dermatitis because it provides actions similar to steroids but with relatively fewer side effects [32].

Vitiligo is an idiopathic-acquired depigmentation disorder. Narrow-band UVB light therapy and oral cortisone or methotrexate have been used as a treatment for active stage vitiligo, but these treatment modalities may cause certain side effects, especially in children. In a study, the effects of UVB alone, glycyrrhizin alone, and combination therapy of both the UVB and glycyrrhizin on active stage vitiligo were compared. Positive results were observed for all three treatments, with the combination therapy of glycyrrhizin and UVB being the most effective option [33]. In another study, it was observed that patients suffering from vitiligo experience inflammation in the dermis and have higher levels of enzymes IL-1b and IL-18 [34]. Glycyrrhizin has the potential to inhibit inflammatory cascade. Hence, the anti-inflammatory properties of glycyrrhizin can also explain its positive effects on vitiligo.

Alopecia areata is another skin disorder that is thought to be caused by a T-cell-mediated autoimmune disease. The infiltration of the increased number of $T$ lymphocytes around the affected follicles has been found in histological examinations. Glycyrrhizin plays a role of an immunoregulator through the inhibition of activation of $T$ cells and cytokines which are generated by CD4+ and CD8+ T cells. In a Chinese research study including children aged 2-14 years; it was observed that both treatments, including glycyrrhizin tablets alone and glycyrrhizin tablets along with total glucosides of paeony capsule, were effective for treating alopecia areata. Another Chinese study demonstrated the positive effects of glycyrrhizin compound along with topical $2 \%$ minoxidil in patients with alopecia areata [35]. 
Table 1: Pharmacological by licorice (G. glabra)

\begin{tabular}{|c|c|c|}
\hline Activity & Part/extract/compound & Animal models and cell lines \\
\hline \multirow[t]{2}{*}{ Antidiabetic } & Licorice essence & Decreased blood glucose levels on use for 8 weeks in a group of rats [36] \\
\hline & Lic $\mathrm{E}$ & $\begin{array}{l}\uparrow \text { Adipocytes levels on enhancement of the activation of PPAR } \gamma \text {, positive impact on } \\
\text { adipocyte-oriented diabetics [12] }\end{array}$ \\
\hline \multirow[t]{2}{*}{ Anti-obesity } & LFO & $\uparrow$ Beta-oxidation - $\downarrow$ fat mass and body fat by lipogenesis prohibition [7] \\
\hline & $\begin{array}{l}\text { Frozen dried powder of ethanolic } \\
\text { licorice extract }\end{array}$ & $\downarrow$ Intestinal absorption of dietary fat $\uparrow$ Serum triglyceride levels $\uparrow$ Excretion of fat content in feces [17] \\
\hline \multirow[t]{5}{*}{ Hepatoprotective effect } & Hispaglabridin A & Peroxidation inhibition \\
\hline & G. glabra root extract & 3'-Hydroxy-4'-O-methylglabridin effectively prevents NADH-dependent peroxidation [37] \\
\hline & & $\begin{array}{l}\text { Radioprotective effects through lipid peroxidation in liver microsomes and plasmid pBR322 of rats. } \\
\text { protection }\end{array}$ \\
\hline & & Microsomal membrane- $\downarrow$ peroxidation of lipids [38] \\
\hline & & In vivo animal models, protective effects observed against $\mathrm{CCL}_{4}$-induced liver injuries [39], [40] \\
\hline \multirow[t]{3}{*}{ Anti-ulcer } & Flavonoid-enriched extract & $\downarrow H$. pylori activity through stressing synthesis of proteins, and two enzymes hydroxyl-folate \\
\hline & Licosio-flavan B, Lic A, glabridin, & reductase and DNA gyrase [41] \\
\hline & licoricidin, and glabrene & Inhibition of Helicobacter pylori reproduction [22] \\
\hline \multirow[t]{3}{*}{ Oral Health Disorders } & $\begin{array}{l}\text { Glycyrrhizin-free licorice } \\
\text { Licorice mouthwash }\end{array}$ & $\begin{array}{l}\text { Inhibition of biofilm formation and growth of UA159 Streptococcus mutants on use of } 16 \mu \mathrm{g} / \mathrm{mL} \text { of } \\
\text { extract [42] }\end{array}$ \\
\hline & & Relieves mouth dryness $\uparrow$ Flow rate of saliva \\
\hline & & Sweet flavor of licorice - improved saliva secretion, improved taste receptors [24] \\
\hline \multirow[t]{2}{*}{ Antidepressant } & Liquiritin & Antidepressant effects on chronic stress \\
\hline & Carbenoxolone & Sedative and muscle-relaxant activity in genetically epilepsy prone rats (GEPRs) [43] \\
\hline \multirow[t]{12}{*}{ Anti-cancer } & Glycyrrhizic acid & AKT/mTOR signal stressed on endometrial and breast cancer cells \\
\hline & Mixed extracts & Leukemia cells proliferation inhibition [44] \\
\hline & Flavonoid-rich part & In vivo and in vitro studies, proliferation inhibition, induced cell cycle arrest, autophagy, \\
\hline & Ethanol extract & differentiation, apoptosis, suppressing metastasis, angiogenesis, sensitizing radiotherapy or \\
\hline & Lic E & chemotherapy [27] \\
\hline & $\begin{array}{l}\text { Topazolin, gancaonin } \mathrm{P} \text {, gancaonin } \mathrm{O} \text {, } \\
\text { Lic B and glyasperin A }\end{array}$ & $\begin{array}{l}\text { Cytotoxic effects against human oral squamous cell carcinoma cell lines as compared to normal } \\
\text { cells [45] }\end{array}$ \\
\hline & Isoliquiritigenin & G1 cell cycle arrest and apoptosis induced in MCF-7 human breast cancer cells [46] \\
\hline & & Antiproliferative properties against MCF-7 [47] \\
\hline & & Potent cytotoxic effects [28] \\
\hline & & $\uparrow$ Cytotoxic activity against human oral squamous carcinoma cell line HSC-2 [48] \\
\hline & & $\begin{array}{l}\text { Human non-small cell lung cancer A549 cell line proliferation inhibition, induced apoptosis and } \\
\text { locked progression of cell cycle in G1 phase [49] }\end{array}$ \\
\hline & & Prostate cancer growth inhibitor [50] \\
\hline \multirow[t]{2}{*}{ Anti-asthma } & Lic A & NF-kB activation by TNF $\alpha$ inhibited, through the inhibition of activation of IkB kinase complex [30] \\
\hline & Flavonoids & Suppressed eosinophilic lung inflammation, levels of IgE, IL-13, IL-5, IL-3个Activity of INF- $\gamma$. [51] \\
\hline \multirow[t]{3}{*}{ Skin disorders } & Lic A & In-vitro study, $\downarrow$ prostaglandin E2 significantly, $\downarrow$ activation of tumor necrosis factor- $\alpha$-induced \\
\hline & Glycyrrhizin & nuclear factor $\kappa B$ [52] \\
\hline & & $\begin{array}{l}\text { Licorice gel dose dependently leads to a reduction in edema, erythema score and itching sense } \\
\text { Effective treatment for atopic dermatitis with relatively less side effects [32] }\end{array}$ \\
\hline
\end{tabular}

\section{Conclusion}

The use of phytopharmaceuticals has escalated in the world as the number of side effects of allopathic medicine are greater. This formed the basis for plant phytochemical and pharmacological investigation. This review forms a basis for further investigations of plant pharmacological and phytochemical properties. The studies observed led to the observation of therapeutic values possessed by licorice. Glycyrrhiza possesses innumerable health benefits including its role as antidiabetic, anti-depressant, anti-obesity, antioxidant, anti-inflammatory, anti-allergic, anti-cancerous, antiulcer, and liver protective properties among many others. The chemical constituents of licorice could serve as "lead" for the treatment of various ailments and forthcoming disorders. Thus, the review presents a direction for future investigations and research studies on licorice to produce medicinally vital drugs including it.

\section{References}

1. Dogan SC, Baylan M, Erdoğan Z, Küçükgül A, Bulancak A. The effects of Licorice (Glycyrrhiza glabra) root on performance, some serum parameters and antioxidant capacity of laying hens. Braz J Poult Sci. 2018;20(4):699-706.

2. Wang X, Zhang H, Chen L, Shan L, Fan G, Gao X. Liquorice, a unique "guide drug" of traditional Chinese medicine: A review of its role in drug interactions. J Ethnopharmacol. 2013;150(3):781-90. https://doi.org/10.1016/j.jep.2013.09.055

PMid:24201019

3. Kao TC, Wu CH, Yen GC. Bioactivity and potential health benefits of licorice. J Agric Food Chem. 2014;62(3):542-53. https://doi.org/10.1021/jf404939f

PMid:24377378

4. Nazari S, Rameshrad M, Hosseinzadeh $\mathrm{H}$. Toxicological effects of Glycyrrhiza glabra (Licorice): A review. Phytother Res. 2017;31(11):1635-50. https://doi.org/10.1002/ptr.5893 PMid:28833680

5. Kim KJ, Choi JS, Kim KW, Jeong JW. The anti-angiogenic activities of glycyrrhizic acid in tumor progression. Phytother Res. 2013;27(6):841-6. https://doi.org/10.1002/ptr.4800 PMid:22899320

6. Weidner C, de Groot JC, Prasad A, Freiwald A, Quedenau C Kliem M, WitzkeA, et al.Amorfrutins are potent antidiabetic dietary natural products. Proc Natl Acad Sci. 2012;109(19):7257-62.

7. Tominaga, Y, Nakagawa K, Mae T, Kitano M, Yokota S, Arai T, et al. Licorice flavonoid oil reduces total body fat and visceral fat in overweight subjects: A randomized, double-blind, placebocontrolled study. Obes Res Clin Pract. 2009;3(3):1-4. https://doi. org/10.1016/j.orcp.2009.04.005

PMid:24345587

8. Tanideh N, Rokhsari P, Mehrabani D, Mohammadi Samani S, Sabet Sarvestani F, Ashraf MJ, Koohi Hosseinabadi O, 
Shamsian S, Ahmadi N. The Healing Effect of Licorice on Pseudomonas aeruginosa Infected Burn Wounds in Experimental Rat Model. World J Plast Surg. 2014 Jul;3(2):99-106.

PMID: 25489532; PMCID: PMC4236996.

9. Hayashi $H$, Sudo $H$. Economic importance of licorice. Plant Biotechnol. 2009;26(1):101-4.

10. Omar HR, Komarova I, El-Ghonemi M, et al. Licorice abuse: time to send a warning message. Ther Adv Endocrinol Metab. 2012;3(4):125-138. doi:10.1177/2042018812454322

11. Yang R, Wang LQ, Yuan BC, Liu Y. The pharmacological activities of licorice. Planta Med. 2015;81(18):1654-69. https:// doi.org/10.1055/s-0035-1557893

PMid:26366756

12. Sawada K, Yamashita $\mathrm{Y}$, Zhang T, Nakagawa K, Ashida H. Glabridin induces glucose uptake via the AMP-activated protein kinase pathway in muscle cells. Mol Cell Endocrinol. 2014;393(1):99-108. https://doi.org/10.1016/j.mce.2014.06.009 PMid:24953974

13. Park HG, Bak EJ, Woo GH, Kim JM, Quan Z, Kim JM, et al. Licochalcone $\mathrm{E}$ has an antidiabetic effect. J Nutr Biochem. 2012;23(7):759-67. https://doi.org/10.1016/j. jnutbio.2011.03.021

PMid:21840191

14. Zadeh JB, Kor ZM, Goftar MK. Licorice (Glycyrrhiza glabra Linn) as a valuable medicinal plant. Int J Adv Biol Biomed Res. 2013;1(10):1281-8.

15. Li W, Li S, Higai K, Sasaki T, Asada Y, Ohshima S, et al. Evaluation of licorice flavonoids as protein tyrosine phosphatase 1B inhibitors. Bioorg Med Chem Lett. 2013;23(21):5836-9. https://doi.org/10.1016/j.bmcl.2013.08.102 PMid:24047800

16. Aoki F, Honda S, Kishida H, Kitano M, Arai N, Tanaka H, et al. Suppression by licorice flavonoids of abdominal fat accumulation and body weight gain in high-fat diet-induced obese C57BL/6J mice. Biosci Biotechnol Biochem. 2007;71(1):206-14. https:// doi.org/10.1271/bbb.60463

PMid:17213668

17. Malik ZA, Sharma PL. An ethanolic extract from licorice (Glycyrrhiza glabra) exhibits anti-obesity effects by decreasing dietary fat absorption in a high fat diet-induced obesity rat model. Int J Pharm Sci Res. 2011;2(11):3010-18. https://doi. org/10.13040/IJPSR.0975-8232.

18. van Rossum TG, Vulto AG, Hop WC, Schalm SW. Glycyrrhizininduced reduction of ALT in European patients with chronic hepatitis C. Am J Gastroenterol. 2001;96(8):2432-7. https://doi. org/10.1111/j.1572-0241.2001.04049.x

19. Al-Razzuqi RA, Al-Jawad FH, Al Hussaini JA, Al-Jeboori AA. Hepatoprotective effect of Glycyrrhiza glabra in carbon tetrachloride-induced model of acute liver injury. J Phys Pharm Adv. 2012;2(7):259-63.

20. Jung JC, Lee YH, Kim SH, Kim KJ, Kim KM, On S, et al. Hepatoprotective effect of licorice, the root of Glycyrrhiza uralensis Fischer, in alcohol-induced fatty liver disease. BMC Complement Altern Med. 2016;16:19. https://doi.org/10.1186/ s12906-016-0997-0

PMid:26801973

21. Jalilzadeh-Amin G, Najarnezhad V, Anassori E, Mostafavi $\mathrm{M}$, Keshipour H. Antiulcer properties of Glycyrrhiza glabra L. extract on experimental models of gastric ulcer in mice. Iran $J$ Pharm Res. 2015;14(4):1163-70. PMid:26664383

22. Fukai T, Marumo A, Kaitou K, Kanda T, Terada S, Nomura T. Anti-Helicobacter pylori flavonoids from licorice extract. Life Sci. 2002;71(12):1449-63. https://doi.org/10.1016/ s0024-3205(02)01864-7

\section{PMid:12127165}

23. Dunlap TL, Wang S, Simmler C, Chen SN, Pauli GF, Dietz BM, et al. Differential effects of Glycyrrhiza species on genotoxic estrogen metabolism: Licochalcone a downregulates P450 1B1, whereas isoliquiritigenin stimulates it. Chem Res Toxicol. 2015;28(8):1584-94. https://doi.org/10.1021/acs. chemrestox.5b00157

PMid:26134484

24. Yu IC, Tsai YF, Fang JT, Yeh MM, Fang JY, Liu CY. Effects of mouthwash interventions on xerostomia and unstimulated whole saliva flow rate among hemodialysis patients: A randomized controlled study. Int J Nurs Stud. 2016;63:9-17. https://doi. org/10.1016/j.jinurstu.2016.08.009

PMid:27565424

25. Hasanein P. Glabridin as a major active isoflavan from Glycyrrhiza glabra (licorice) reverses learning and memory deficits in diabetic rats. Acta Physiol Hung. 2011 Jun;98(2):22130. https://doi.org/ 10.1556/APhysiol.98.2011.2.14

PMID: 21616781.

26. Chakravarthi KK, Avadhani R. Enhancement of hippocampal CA3 neuronal dendritic arborization by Glycyrrhiza glabra root extract treatment in Wistar albino rats. J Nat Sci Biol Med. 2014;5(1):25-9. https://doi.org/10.4103/0976-9668.127279 PMid:24678192

27. Tang ZH, Li T, Tong YG, Chen XJ, Chen XP, Wang YT, Lu JJ. A systematic review of the anticancer properties of compounds isolated from licorice (gancao). Planta Med. 2015;81(18):167087. https://doi.org/10.1055/s-0035-1558227 PMid:26695708

28. Yoon G, Jung YD, Cheon SH. Cytotoxic allylretrochalcone from the roots of Glycyrrhiza inflata. Chem Pharm Bull (Tokyo). 2005;53(6):694-5. https://doi.org/10.1248/cpb.53.694 PMid:15930786

29. Rahman MS, Rashid MA. Antimicrobial activity and cytotoxicity of Eclipta prostrata [Internet]. Vol. 8, Oriental Pharmacy and Experimental Medicine. Kyung Hee Oriental Medicine Research Center; 2008. p. 47-52. Available from: http://dx.doi. org/10.3742/OPEM.2008.8.1.047

30. Kim SH, Yang M, Xu JG, Yu X, Qian XJ. Role of licochalcone A on thymic stromal lymphopoietin expression: Implications for asthma. Exp Biol Med (Maywood). 2015;240(1):26-33. https:// doi.org/10.1177/1535370214545020 PMid:25055998

31. Icer MA, Sanlier N. A review: Pharmacological effects of licorice (Glycyrrhiza glabra) on human health. 2017;6(1):12-26.

32. Kwon YJ, Son DH, Chung TH, Lee YJ. A review of the pharmacological efficacy and safety of licorice root from corroborative clinical trial findings. J Med Food. 2020;23(1):1220. https://doi.org/10.1089/jmf.2019.4459 PMid:31874059

33. Mou KH, Han D, Liu WL, Li P. Combination therapy of orally administered glycyrrhizin and UVB improved active-stage generalized vitiligo. Braz J Med Biol Res. 2016;49(8):e5354. https://doi.org/10.1590/1414-431X20165354 PMid:27464024

34. Allam M, Riad H. Concise review of recent studies in vitiligo. Qatar Med J. 2013;2013(2):1-19. https://doi.org/10.5339/ qmj.2013.10 PMid:25003059

35. Xiong X-c, Ding X-j, Zhang H, Hou X-q, Xiong F, Mou Y-Z: Treatment of alopecia areata with compound glycyrrhizin and topical minoxidil (J). Chin J Aesthetic Med 2013;11:1195-7.

36. Kataya HH, Hamza AA, Ramadan GA, Khasawned MA. Effect of licorice extract on the complications of diabetes nephropathy in rats. Drug Chem Toxicol. 2011;34(2):101108. https://doi.org/1 
$0.3109 / 01480545.2010 .510524$

PMid:21314459

37. Haraguchi $\mathrm{H}$, Yoshida $\mathrm{N}$, Ishikawa $\mathrm{H}$, Tamura $\mathrm{Y}$, Mizutani $\mathrm{K}$, Kinoshita T. Protection of mitochondrial functions against oxidative stresses by isoflavans from Glycyrrhiza glabra. J Pharm Pharmacol. 2000;52(2):219-23. https://doi. org/10.1211/0022357001773724 PMid:10714953

38. Shetty TK, Satav JG, Nair CK. Protection of DNA and microsomal membranes in vitro by Glycyrrhiza glabra L. against gamma irradiation. Phytother Res. 2002;16(6):576-8. https:// doi.org/10.1002/ptr.927

PMid:12237818

39. Huo HZ, Wang B, Liang YK, Bao YY, Gu Y. Hepatoprotective and antioxidant effects of licorice extract against $\mathrm{CCl}(4)$-induced oxidative damage in rats. Int J Mol Sci. 2011;12(10):6529-43. https://doi.org/10.3390/ijms12106529

PMid:22072903

40. Yin G, Cao L, Xu P, Jeney G, Nakao M, Lu C. Hepatoprotective and antioxidant effects of Glycyrrhiza glabra extract against carbon tetrachloride $(\mathrm{CCl}(4))$-induced hepatocyte damage in common carp (Cyprinus carpio). Fish Physiol Biochem. 2011;37(1):209-16. https://doi.org/10.1007/s10695-010-9436-1 PMid:20865324

41. Asha MK, Debraj D, Prashanth D, Edwin JR, Srikanth HS, Muruganantham N, et al. In vitro anti-Helicobacter pylori activity of a flavonoid rich extract of Glycyrrhiza glabra and its probable mechanisms of action. J Ethnopharmacol. 2013;145(2):581-6. https://doi.org/10.1016/j.jep.2012.11.033 PMid:23220194

42. Ahn SJ, Song YD, Mah SJ, Cho EJ, Kook JK. Determination of optimal concentration of deglycyrrhizinated licorice root extract for preventing dental caries using a bacterial model system. J Dent Sci. 2014;9(3):214-20.

43. Gareri P, Condorelli D, Belluardo N, Russo E, Loiacono A, Barresi $\mathrm{V}$, et al. Anticonvulsant effects of carbenoxolone in genetically epilepsy prone rats (GEPRs). Neuropharmacology. 2004;47(8):1205-16. neuropharm.2004.08.021 PMid: 15567430

44. He SQ, Gao M, Fu YF, Zhang YN. Glycyrrhizic acid inhibits leukemia cell growth and migration via blocking AKT/mTOR/ STAT3 signaling. Int J Clin Exp Pathol. 2015;8(5):5175. PMid:26191214

45. Fukuchi K, Okudaira N, Adachi K, Odai-Ide R, Watanabe S,
Ohno $\mathrm{H}$, et al. Antiviral and antitumor activity of licorice root extracts. In Vivo. 2016;30(6):777-85. https://doi.org/10.21873/ invivo.10994

PMid:27815461

46. Jo E., Kim S., Ra J., Kim S., Cho S., Jung J., Yang S., Park J., Hwang J. And Aruoma O. (2005) 'Chemopreventive properties of the ethanol extract of chinese licorice () root: induction of apoptosis and G1 cell cycle arrest in MCF-7 human breast cancer cells', Cancer Letters. Elsevier BV, 230(2), pp. 239-247. doi: 10.1016/j.canlet.2004.12.038

47. Dong S, Inoue A, Zhu Y, Tanji M, Kiyama R. Activation of rapid signaling pathways and the subsequent transcriptional regulation for the proliferation of breast cancer MCF-7 cells by the treatment with an extract of Glycyrrhiza glabra root. Food Chem Toxicol. 2007 Dec;45(12):2470-8. doi: 10.1016/j. fct.2007.05.031. Epub 2007 Jun 24.

PMID: 17664038.

48. Nomura T, Fukai T, Akiyama T. Chemistry of phenolic compounds of licorice (Glycyrrhiza species) and their estrogenic and cytotoxic activities. Pure Appl Chem. 2002;74(7):1199-206.

49. Hsu YL, Kuo PL, Chiang LC, Lin CC. Isoliquiritigenin inhibits the proliferation and induces the apoptosis of human non-small cell lung cancer A549 cells. Clin Exp Pharmacol Physiol. 2004;31(7):414-8. https://doi. org/10.1111/j.1440-1681.2004.04016.x

PMid:15236626

50. Cuendet M, Guo J, Luo Y, Chen S, Oteham CP, Moon RC, van Breemen RB, Marler LE, Pezzuto JM. Cancer chemopreventive activity and metabolism of isoliquiritigenin, a compound found in licorice. Cancer Prev Res (Phila). 2010 Feb;3(2):221-32. doi: 10.1158/1940-6207.CAPR-09-0049. Epub 2010 Jan 12. PMID: 20068129;

PMCID: PMC2818593

51. Ma C, Ma Z, Liao XL, Liu J, Fu Q, Ma S. Immunoregulatory effects of glycyrrhizic acid exerts anti-asthmatic effects via modulation of Th1/Th2 cytokines and enhancement of CD4(+) CD25(+)Foxp3+ regulatory T cells in ovalbumin-sensitized mice. J Ethnopharmacol. 2013 Jul 30;148(3):755-62. doi: 10.1016/j. jep.2013.04.021. Epub 2013 Apr 28.

PMID: 23632310

52. Sulzberger M, Worthmann AC, Holtzmann U, Buck B, Jung KA, Schoelermann AM, et al. Effective treatment for sensitive skin: 4-t-butylcyclohexanol and licochalcone A. J Eur Acad Dermatol Venereol. 2016;30 Suppl 1:9-17.https://doi.org/10.1111/ jdv.13529

PMid:26805417. 